\title{
ANTROPOLOGÍA
}

\section{MUJER Y CUIDADOS: \\ ¿HISTORIA DE UNA RELACIÓN NATURAL?}

Montserrat Antonín Martín,

Diplomada en Enfermería y Licenciada en Antropología Social y Cultural *

Pilar Flor Pérez,

Diplomada en Enfermería *

Joaquín Tomás Sabado,

Diplomado en Enfermería y Doctor en Psicología. *

*Profesores de la E. U. INFERMERIA "GIMBERNAT" (U.A.B.)

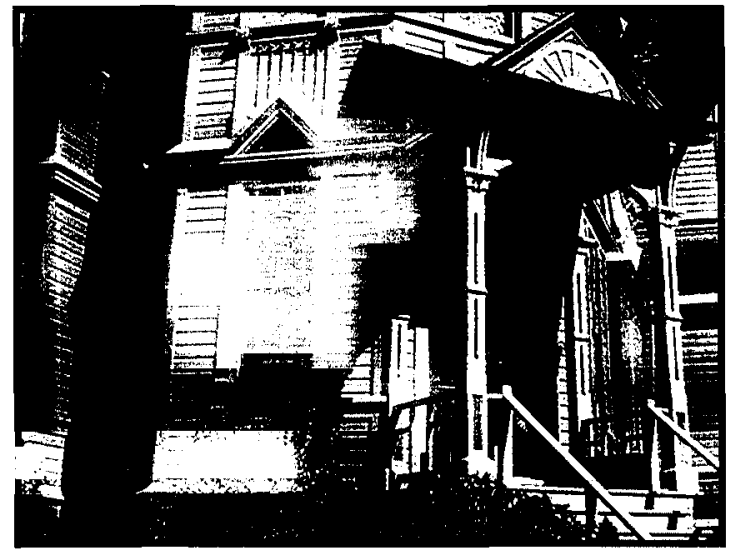

WOMEN AND CARE: A NATURAL RELATION HISTORY?

7 he present study originates in a study presented by some other teachers of our own

I school, in 1995, about the historic evolution of relationship nursing versus gender. This study shows why nursing tasks have been seen as something innate and natural in women and have always been interpreted as a "secondary role tasks".

That link between women and care has been historically interpreted as something natural never discussed. The origins of that sort of link run parallel to the self-evolution of nursing and could be understood by means of analysing the systems of social relationship established between nature/culture, domestic environments and public environments, and productive and non-productive jobs...
The purpose of this paper lies in the convenience of an up-to-date analysis about functional relationships established between gender and nursing that allow to deepen into the nature of sociocultural influence over a professional development, in order to enlighten the question of why has nursing historically been considered a "secondary role" profession.

Key words: nursing, gender, socio-cultural, influence, systems, relationship

\section{RESUMEN}

$\mathrm{E}$ ste trabajo tiene sus orígenes en un estudio que profesores de nuestra escuela realizaron en el año 1995 acerca de la evolución histórica de la relación enfermería y género. Este estudio puso de manifiesto porqué las tareas de enfermería concebidas como algo innato y natural de la mujer, han sido entendidas como un "rol de segundo orden".

El vínculo entre la mujer y los cuidados ha sido históricamente asumido como algo natural y raramente cuestionado. Los orígenes de esta vinculación, que son paralelos a la propia evolución de la enfermería, pueden ser entendidos mediante el análisis de los sistemas de relaciones socialmente establecidos entre naturaleza/cultura, ámbito doméstico/público y trabajo productivo/improductivo. 
El propósito de esta comunicación es llevar a cabo un análisis actualizado acerca de las relaciones funcionales establecidas entre género y enfermería, que permitan profundizar en la naturaleza de la influencia socio-cultural sobre el desarrollo profesional y aportar luz a la cuestión de porqué históricamente la enfermería ha sido considerada como un trabajo de segundo orden.

Palabras clave: Enfermería, Genero, Influencia socio-cultural, Sistemas de Relaciones.

\section{INTRODUCCIÓN}

Este trabajo tiene sus orígenes en un estudio que profesores de nuestra escuela realizaron en el año 1995 acerca de la evolución histórica de la relación enfermería y género. Parece Obvia la relación entre mujer y enfermería como trayectorias paralelas y estrechamente vinculadas. Esta vinculación que vivimos como algo "natural" tiene unos orígenes que podemos analizar y que plantean cuestiones como:

- ¿ser mujer ha sido un factor determinante para el desarrollo profesional de la enfermería?

- ¿que tipo de influencia tiene la "cultura" sobre la trayectoria profesional de enfermería?

- ¿en que nos basamos para sustentar que el concepto de arte doméstico sigue pesando sobre la profesión?

- ¿por qué históricamente el trabajo de enfermería se ha considerado como un trabajo de segundo orden?

Estas cuestiones plantean a su vez, la necesidad de realizar una revisión crítica y actual sobre las principales relaciones funcionales establecidas entre establecidas entre género y enfermería, que permitan profundizar en la naturaleza de la influencia socio-cultural sobre el desarrollo profesional y aportar luz a la cuestión de porqué históricamente la enfermería ha sido considerada como un trabajo de segundo orden.

Para ello nos centraremos en diversos aspectos para analizar esta relación "incuestionablemente natural".

\section{EL HECHO DE LA MATERNIDAD}

Sólo hay algo que diferencia universalmente a hombres y mujeres: su fisiología. Las implicaciones que conllevan las diferencias fisiológicas hacen que la mujer presente una exclusiva y específica función procreadora/reproductora que la sitúa cercana a la naturaleza. Lógicamente y durante un cierto período de tiempo es la mujer quien vela por la supervivencia de su hijo/a, puesto que de ella depende directamente su alimentación. El vínculo que se establece entre madre e hijo/a durante este período de tiempo se considera "natural" y se prolonga de hecho naturalmente hasta que el niño/a adquiera cierto grado de habilidad y raciocinio que le permita "valerse", en términos relativos, por sí mismo.

La relación que se establece entre madre e hijo/a es tomada pues como una primera limitación para la mujer aunque ésta no lo sea en sí misma sino que viene impuesta por las limitaciones que sufren sus propios hijos/as.

La maternidad se describe así en términos biologicistas o reduccionistas. La limitación no debe ser entendida como sinónimo de restricción. A pesar de ello, esta primera asociación de ideas confiere ya un marco conceptual donde incluir la "natural limitación de la mujer". Si añadimos el hecho de que esta limitación incide directamente en la movilidad social de la mujer es mucho más sencillo que ésta quede confinada a determinados contextos y funciones sociales.

Implícito a este discurso encontramos una segunda asociación: la mujer y la naturaleza. Como hemos visto anteriormente, la función reproductiva de la mujer viene dada por su naturaleza. Los lazos que unen a madres e hijos/as son "naturales". La limitación durante los primeros años de vida que éstos imponen especialmente respecto a la movilidad social de la madre es natural y por tanto también es natural que esta se encuentre circunscrita al círculo doméstico.

En definitiva no parece existir nada más próximo a la naturaleza que la mujer. ¡Y nada más erróneo! No por cuanto no sea cierta esta relación sino y como afirma Otner por cuanto no es ni más cercana ni más lejana a la relación que el hombre puede establecer respecto a dicha naturaleza. 
La mayoría de culturas reconocen y establecen diferencias entre la naturaleza y por consiguiente entre el "mundo natural" y la propia sociedad en la cual se encuentran inmersos. El hombre, por el hecho de estar liberado fisiológicamente de toda condición reproductora, parece quedar liberado de toda relación con la naturaleza y por tanto circunscribirse al ámbito de la cultura. En palabras de Otner la cultura puede trascender, doblegar y controlar la naturaleza. Si la mujer, por su rol reproductor, es asociada por el propio hombre a la naturaleza y éste por el mismo concepto se asocia a si mismo con el ámbito de la cultura, la relación que nace entre ambos estará determinada, como es del todo lógico, por la misma que sostiene la dicotomía naturaleza/cultura es decir, el hombre ejercerá su dominio y control sobre la mujer.

\section{DOMÉSTICO VERSUS PÚBLICO O LA PRODUCTIVIDAD DEL TRABAJO}

Hasta aquí la primera de las supuestas limitaciones que el hecho de la maternidad impone a las mujeres, en cuanto que reduce durante un tiempo determinado su movilidad social circunscribiéndola al círculo doméstico.

Las definiciones sobre el concepto "doméstico" llevan implícitas una relación de subordinación. Al igual que la cultura llega a dominar a la naturaleza, la esfera de lo público confiere un estatus social y una autoridad incuestionablemente superior o de dominio sobre la esfera doméstica.

La dicotomía público/doméstico, finalmente, confiere también significado a las relaciones de producción y a las actividades económicas tanto femeninas como masculinas. Así pues, la esfera de lo público y lo doméstico conlleva una clara división de roles y, por lo tanto, de las tareas que cada uno de los sexos debe llevar a cabo.

Sacks realizó en 1979 un análisis del trabajo de los hombres y las mujeres como determinantes de su estatus, explicando de una forma coherente el origen de la división sexual del trabajo. Propone que el alejamiento de las mujeres de la producción social se debe precisamente a no ser su trabajo considerado dentro de la esfera pública-social. Rosaldo, por su parte, afirma que los sistemas de clasificación social raramente dan cabida a los intereses de las mujeres, por lo que es lógico que estos no se comprendan a nivel público. Nosotros nos atrevemos a decir que no es que no se comprendan sino que se omiten.

El trabajo doméstico que las mujeres desarrollan no ha sido contemplado como un trabajo productivo en su más pura formulación, es decir, carece de valor al estar limitado al ámbito doméstico/familiar. Así pues, no es de extrañar que si, históricamente, la mujer ha estado confinada rigurosamente, por imposiciones sociales, al hogar, la enfermería naciera adoptando un carácter de arte doméstico. Su trabajo se orientó inicialmente como recursos dirigidos a su propia familia y este esfuerzo de servicio, se extendió al cuidado de los ancianos e individuos que enfermaban en su comunidad.

Es precisamente esta orientación doméstica el factor que determinó la posición de la mujer siendo relegada a roles circunscritos como el rol de esposa, madre y, por supuesto, cuidadora. Estos roles no suponen ningún valor de intercambio sino, simplemente, un valor de consumo interno o privado.

Pero aun cuando las mujeres fueron incorporadas masivamente a la producción social, el trabajo productivo no ha servido para crear una base para la igualdad. En primer lugar, el trabajo realizado por las mujeres es automáticamente categorizado como trabajo femenino y, por ello, desvalorizado por completo. Las mujeres debieron asumir aquellas tareas podríamos decir de "segundo orden", tareas aburridas, repetitivas, sencillas.

De esta concepción a la infravaloración del trabajo realizado por las mujeres sólo hay un paso, de éste a la subordinación, ninguno.

La historia nos muestra como en la Edad Media, el fervor religioso y la motivación hacia el cuidado de los demás fueron los pilares que fundamentaban el trabajo de enfermería. Con el paso del tiempo se puso de manifiesto que el amor y la dedicación no bastaban por sí solos.

Si extrapolamos lo analizado anteriormente y lo llevamos a las funciones que enfermería ha desarrollado a lo largo de la historia, no es difícil entender porqué las tareas de enfermería surgidas como algo innato y natural, han sido entendidas como un rol de "segundo orden". 


\section{CONCLUSIONES}

Podemos concluir a partir de este análisis que las relaciones que se establecen entre género y enfermería demuestran la existencia de un sistema "casi racional" de discriminaciones históricas dado, que la historia de la enfermería ha discurrido íntimamente ligada a la historia de la mujer

No obstante, no quisiéramos finalizar transmitiendo la idea de que la relación género-enfermería está únicamente ligada a conceptos negativos. En la actualidad la enfermería está sufriendo cambios trascendentales a los que no son ajenos la revolución que ha supuesto una mayor accesibilidad a la esfera de lo social y por consiguiente al ámbito productivo. Además, el paradigma inicial de la enfermera vocacional ha sufrido una profunda y decisiva transformación que ha supuesto para la profesión una intervención profesional más global y un trabajo interdisciplinario, así como la consolidación como disciplina científica con todo lo que ello ha comportado para la afirmación de nuestro rol autónomo profesional.

\section{BIBLIOGRAFÍA}

- Antonin, M.; Flor, P.; Llinas, M.; Tarrech, M.: (1997) Infermeria, reflex històric de la dona ?. Ressò d'Infermeria 1.

- Donahue, M.P.: (1985) Historia de la Enfermería,. Ediciones Doyma. Barcelona

- Hernández Conesa, J.: (1995) Historia de la Enfermería. Análisis histórico de los cuidados de enfermería. Interamericana McGraw-Hill. Madrid.

- Otner, S.B.: (1979) “¿Es la mujer con respecto al hombre lo que la naturaleza respecto a la cultura?", Harris, O.; Young, K.; (eds), Antropología y Feminismo.

- Rosaldo, M.Z.: (1979) "Mujer, cultura y sociedad: una visión teórica", Harris, O.; Young, K.; (eds), Antropología y Feminismo.

- Sacks, K.: (1979) "Engels revisitado: las mujeres, la organización de la producción y la propiedad privada", Harris, O.; Young, K.; (eds), Antropología y Feminismo.

- Stolke, V: (1982) "Las mujeres y el trabajo", en M. León (eds), Debate sobre la mujer en América Latina y el Caribe.

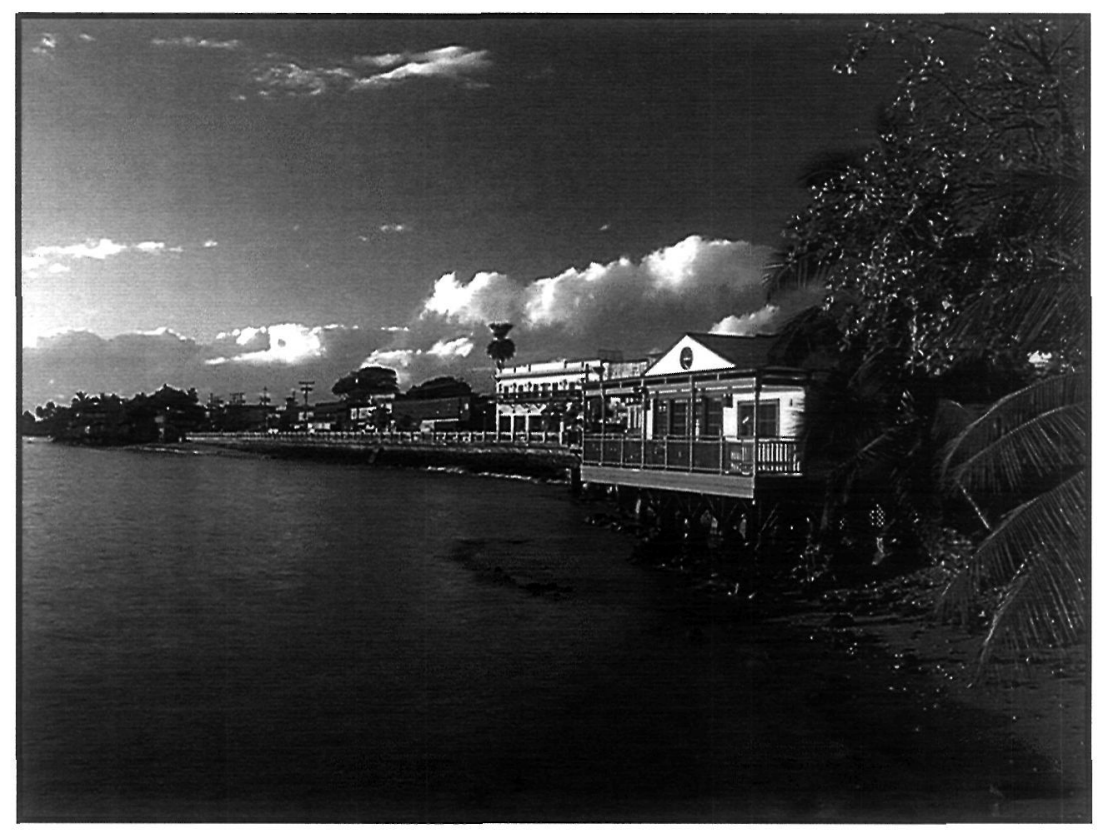

